fitted with what is known as "extension towers" which consist of tubing from fifteen to twenty feet long, carrying a nozzle at the tip. This method has been used mostly by the United States Government in roadside spraying in the moth-infested area.

In some cases, it is not possible to secure as good results with the towers as it is with the long nozzle, and this is particularly true when the wind is contrary.

In calculating the cost of treating shacle trees and woodland areas, a reasonable amount must be allowed for depreciation of apparatus. We consider that 20 per cent should be allowed annually on the machines, and 50 per cent on the hose. The average cost of spraying shade trees, both large and small, is between fifteen and twenty cents per tree.

One other improvement which I neglected to mention, which will be used in this year's machines is the high tension Bosch magnetos instead of batteries for ignition, and mechanical oilers in place of gravity feed. The use of the magnetos will strengthen the power and the oilers will climinate excess oil in the engine base.

From our experience the different spraying outfits may be rated as follows: First, the hand pump, agitation not good, expensive to use when much work is to be done; second, small power outfits, not much better than hand sprayers; if the proper agitation is secured too much power is consumed and not enough remains to give efficient results at the nozzle. We find that efficiency and economy must be considered at the same time, and high class outfits, alone, will give these results.

President Sanderson: The next paper, by Mr. Worsham, who is not here, will be read by the secretary.

\title{
SPRAYING APPARATUS FOR SCALE INSECTS
}

\section{By E. L. Wonsham, State Entomologist, Georgia}

The title of this paper designates a consideration of spraying apparatus and accessories, particularly with reference to their use in controlling the Coccidx. Generally speaking, any good modern pump is equally well adapted to spraying both fungicides and insecticides. In certain respects, however, which are primarily concerned with the physical nature of the spray material, the efficiency of the different types of spray pumps is somewhat variable. The reason for this variation is hereinafter discussed more fully under the head of pump construction. 
There is spraying apparatus of all kinds and sizes, and the selection of an outfit is, therefore, based on its service requirements. Beginning with the smallest of all, the bucket pumps which may be had for a few dollars, the sizes and costs will increase on a more or less graduated scale up to the 200-gallon power pumps which cost several hundred dollars.

- Strong competition in the spray machinery business is responsible for the rapid improvement in the construction of pumps and accessories. It is now possible for the purchaser to obtain good, durable and efficient pumps from a number of manufacturers and at a cost entirely commensurate with their value. Individual operators have a large field in which to exercise their choice, though such choice would necessarily be founded more upon some peculiar mechanical device than upon cost.

\section{Bucket and Knapsack Pumps}

These two styles are grouped together because their field of usefulness is so limited. With sufficiently long leads of hose they may be used on small orchard trees, but they are designed and built ostensibly for use in spraying greenhouse. plants and shrubs. Their relatively small cost places them easily within reach of all who have ornamental plants to protect, both indoors and out, from scale insects, and in this field they make valuable acquisitions to the garden, the greenhouse, and in the growing of small ornamental plants.

The bucket pump as a rule is constructed so as to extend into the bucket, to which it is attached by a clamp: a foot piece extends to the ground and by placing the foot upon this the pump is held in position while it is being worked. The cost varies from $\$ 5$ to $\$ 10$.

The knapsack pump being more portable and somewhat larger, is a more desirable contrivance for use in the sphere above assigned to the bucket pump. It is attached to the back after the fashion of a knapsack and is worked by a lever extending over the operator's shoulder. The details of construction vary between the different manufacturers, but the general plan is much the same in all. They are of five gallons capacity and are equipped with 3-8-inch hose to which any style nozzle may be fitted. The tanks are made of brass or ga'vanized iron and the prices are governed by the metal used in their makeup. The list prices vary from $\$ 10$ to $\$ 18$.

\section{Barrel Pumps}

Barrel pumps, as the name denotes, are pumps intended for mounting in barrels, and their size, cheapness and general efficiency for spraying on both large and small scale make them, perhaps, the most important 
type of spray pump. When fitted out with good accessories they are capable of spraying the largest fruit trees under ordinary conditions and by far the larger part of all orchard spraying is done with pumps of this class. Practically the same principles are incorporated in the manufacture of the different makes, though the details of construction vary greatly.

It may be well in discussing this pump to consider what the essentials of a good pump are.

To begin with, it is necessary to have an air chamber to insure a steady spray, otherwise the spray would be intermittent and pulsating. The air chamber may be either separated from the working parts of the pump or combined with them. In some styles it is on top of the barrel, but in the more satisfactory types it is within, and in the latter the stability of the pump is greater. A large air chamber on the top of the barrel renders it top heavy, and this top heaviness is likely to be responsible for accidents when spraying on rough land.

One feature of the barrel pump that is yet far from perfection is the agitator. In most forms the paddle agitators are used, but these, while they are all that could be desired for spraying materials free of solid matter, will not and can not keep sprays such as the home-made lime and sulphur thoroughly mixed. The tips of the paddles describe an arc of about $45^{\circ}$ and work so slowly that the lime quickly settles to the bottom with the result that the first part of the material as it comes from the barrel carries much more free lime than the last, which has but little.

The question of the agitator for barrel pumps is an important one and one that has not heretofore been satisfactorily solved. It is only in gas power sprays that this feature is perfected. However, for the materials now being used against scale insects which are uniform in composition and carry no solids, an agitator is wholly unnecessary.

The working parts of a pump, namely, the valves, valve seats, plunger and cylinder, should be made of metal resistant to the corrosive action of the spray material. These are usually of brass, bronze, or porcelain, substances not corroded by the action of the liquid.

A pump should be compactly built with all the working parts closely fitted so as to prevent leakage and attendant loss of power. All parts should be easily removable for cleaning purposes and to make repairs. Much trouble may be avoided by using only the best packing for the plunger. The standard asbestos is far superior to leather or cord, being more resistant to the caustic action of the spray and in every way more durable and satisfactory.

The spray pump market supplies a large number of different makes of barrel pumps. Those best known to the author are the "Deming," 
manufactured at Salem, Ohio; the "Friend," manufactured at Gasport, N. Y., the "Gould," at Seneca Falls, N. Y., the "Bean," at Cleveland, Ohio, and the "Hardie," at Hudson, Mich. The last has the pump mounted in the side of the barrel instead of the top, and this feature makes it particularly adaptable for spraying on rough steep hillsides. By building a frame work to the front trucks of a wagon and attaching the barrel thereto, the pump may be operated by the driver from the ground. The frame work being a continuation of the shafts, gives the barrel an angle which brings the pump handle to a position from which it can easily be worked by the driver. This pump when so arranged is especially valuable for use on land not really accessible to a wagon.

Any of the pumps above named are good, reliable makes, and with proper care will last indefinitely. They are sufficiently powerful to generate and consistently maintain pressure for the two leads of hose carrying a total of four nozzles.

\section{Horizontal Pumps}

This type of pump is designed for spraying on an extensive scale. It is larger and more powerful than the barrel pumps and is capable of supplying four leads of hose. The air chamber is of greater capacity and, therefore, capable of storing more air pressure than the smaller types. The plungers are usually differential and thus an equal pressure is exerted on both strokes, making the pumps double acting. With these, as with the barrel pumps, the principle of construction is practically the same. There are many differences of detail, and it is in the details that each manufacturer claims superiority over his competitor.

Horizontal pumps are intended for attaching to wagon tanks of from 100 to 200 gallons' capacity. They may also be bolted to a heavy lead and operated in connection with an ordinary fifty-gallon barrel. Primarily, however, they are designed for tanks and for heavy work on a large scale.

This style of pump may be, and usually is, operated by hand, but it is usually fitted up with a pitman or similar device for connecting to a gas engine. The Bean Pump Company are manufacturers of a pump of this kind that includes a heavy coil spring for equalizing the efforts necessary to operate the pump handle. On one stroke energy is stored into the spring by the pull against its resistance and the resultant compression, and in the return stroke the stored energy contained in the compressed spring is released and the expansion helps the operator in forcing the liquid into the air chamber against full gauge pressure. 
The working parts of horizontal pumps are not immersed in the spray material as is the case with most pumps of smaller size. The air chamber is connected to the material supply by a piece of heavy rubber piping, and is filled by suction. Repairs are more easily effected than with barrel pumps. which have to be removed from the barrels, sometimes when the latter are full of spray material, before the seat of the trouble can be reached.

The cost of the horizontal pump ranges from $\$ 25$ to $\$ 50$. Nearly all the pump manufacturers have their cheaper and their better grades with an accompanying price list to match.

\section{Power Pumps}

Power pumps are of two kinds, (1) gasoline and (2) compressed air or compressed gas. With these machines it is possible to maintain the air pressure at a higher and more constant figure than with hand motive power. The maximum degree of success in spraying against scale insects is obtained only when the spray is driven onto them in a finely divided state and with force. The greater the force the greater the efficiency of the work, all other conditions being equal. Power outfits meet this essential requirement better than those operated by hand, for the reason that they can maintain a higher pressure and hold it practically constant. For general efficiency and labor saving they are superior to other types, especially in large commercial orchards, parks, etc.

\section{Gasoline Power Pumps}

All the leading power pump manufacturers turn out regular power pump outfits and they are giving general satisfaction wherever used. The original purchase price is, of course, much higher than for hand pumps, but thereafter they may be operated at a smaller cost and the additional cost in the beginning represents economy in the end.

Power pumps can certainly maintain high pressure for four leads of hose and have a capacity of 200 gallons per hour. Their greater weight makes them ineligible for use on land of a rough or hilly nature, but on flat land they are the most efficient and most rapid sprayers on the market, and their value as time and money savers is being more generally understood and appreciated than ever before. They are cheaper, too, than at any time in the past. A spraying outfit with gas engine, pump, lead, hose, etc., may be bought for sums varying from $\$ 135$ to $\$ 300$. The gasoline engines may be used for other farm purposes as well.

One feature of the gasoline power outfits, wherein they outclass any other type of pump, is the matter of the agitator. By attaching 
the agitator to the engine, the paddles may be run at a rapid rate of speed and the spray material kept in a violent state of agitation. Where home-made lime and sulphur or other materials carrying solid matter are used this form of power pump is superior to any other.

\section{Compressed Air Pumps}

This class of pump is of two kinds, i.e., those that are air charged at a fixed station, and those that compress the air into a cylinder by means of an apparatus connected with the rear wheels of the spray wagon, Both of these types are worthy of recommendation under certain conditions. Where no part of the spray solution will settle out, as when miscible oils, prepared lime and sulphur, etc., are used, and no agitation thereof is necessary, pumps that are air charged at the renewal station are highly efficient. Pumps that depend on the automatic compression of the air from the turning of the wagon wheels are efficient when the trees are small and can be rapidly sprayed. They are failures among large trees that require some minutes to spray before any advance is made. Neither of these types has adequate agitation equipment and other means must be employed wherever necessary to keep the material well mixed.

\section{Carbonic Acid Gas Pumps}

The working principle of carbonic acid gas pumps is almost identically like the compressed air type, except that the cylinder is charged with carbonic acid gas instead of air. It is an efficient, serviceable pump, but with respect to the agitator it is equally as inefficient as the compressed air pumps.

\section{Spraying Accessories}

No pump, no matter how capable, will give service without the complementary support of good spraying auxiliaries of the best quality and design. As much attention should be given to these as to the pump itself. These accessories consist of hose, extension rod, stop cocks and nozzles.

\section{Hose}

Nothing need be said of this save that it should be of the best quality and ample length. As a matter of economy, it is cheaper to buy the best grade of four-ply goods. This will easily last a full season or longer with proper care. Cheaper grades are quick to leak and are generally unsatisfactory. The better grades of hose cannot be bought for less than fifteen cents per foot. 


\section{Extension Rods}

No spraying outfit is complete without an extension rod. It is an indispensable adjunct in reaching to all parts of the trees, expediting the work and improving the quality of the spraying. Besides these advantages, it is a protection to the operator, enabling him to evade a wetting from the spray mist as it is blown or drifted about. Rods are usually made of 1-4-inch piping and are cut to any desired length based upon the requirements. Bamboo rods are also used for the same purpose. Piping may be cut in short lengths and lengthened or shortened at will to suit the occasion by means of couplings.

\section{Stop Cocks}

Stop cocks are very serviceable and almost imperatively necessary in large spraying operations. By cutting off the flow they prevent waste in moving from tree to tree and are invaluable to successful and economical spraying. There are only a few types, the best of which is the brass stop cock with stuffing box that may be tightened so as to prevent all leakage. This type has a cut-off handle two inches long extending on just one side of the stuffing box and readily cut on or off by the thumb.

\section{Nozzles}

There are nozzles of all kinds and sizes and one must be governed by the requirements in each case. In spraying for scale insects it is of prime importance to use only nozzles throwing a finely divided spray. Maximum good results are obtained from nozzles insuring this important feature.

The best types of nozzles used in Georgia are the Vermorel, Bean, Friend, and Mistry, Jr. These may be attached to the rod singly, in couples, or sets of three or more. In the writer's opinion the best nozzle now on the market is what is called the Mistry, Jr. The Bean Manufacturing Company also make similar nozzles. In this type the construction is exceedingly simple; they do not easily become clogged and are readily cleaned when the flow becomes obstructed. They are without the degorger common to the Vermorel type and the objectionable features occasioned by the catching of these prongs on the limbs, pulling off the fruit, etc., are eliminated. Their extreme simplicity, the ease with which they are cleaned and the rapid and thorough work they insure puts them well at the head of the list in the world of nozzles. 
President Sanderson: These three papers open up a wide field for discussion.

Mr. Srmons: I would say that I feel some hesitation about discussing this problem beside Mr. Worthley, who has so ably presented the matter of spraying in the New England States. He gives some good reasons why the price of rubber has gone up. We hear of the miles of hose they have used. There are some points I glean from these papers, with which I do not entirely agree, but on the whole they are very instructive. Referring to the point made in regard to the use of the barrel pump, and a man maintaining two leads of hose, I would say I would not like to be the man to keep the nozzles busy. There is another point, I note that two of the papers do not advise the use of gear sprayers. We have found in our state that in some respects gear sprayers have given considerable satisfaction. It certainly is to be said they are not designed for treating large trees. We previously had a gasoline engine made in accordance with our own ideas, and the men have absolutely abandoned that engine for the Brown gear sprayer. Now, in regard to the sprayers on the market, it seems to me the manufacturers have been slow to take up some points we have made in regard to spraying machinery. I know at least one firm which continues to make pumps with large air chambers above the barrel, which I believe we all concede is rather impractical. Moreover, the power sprayer is the coming sprayer, and of that kind I would say the Friend seems to be predominant. But, even with that outfit, $I$ believe that they can reduce the weight of the engine. The one we previously used weighed only ninety pounds, and gave satisfaction, while the larger engines, the Goulds and others, weigh from 300 to 400 pounds, and certainly it seems as if they could reduce that weight. I think the suggestion made by Professor Ball in regard to a tower is an excellent one.

Mr. Headuete: Our time is very short, and I think the ground has been thoroughly covered. I wish to touch briefly on one pointspraying by means of compressed air. In large orchards compressed air appears to be one of the very best sources of power. Mr. George Richardson of Tonganoxie, Kan., has gotten together the necessary machinery and has used compressed air for several years in treating his large orchard. He said to mee at Christmas time, "If I did my spraying as most fruit growers do it, I would have to have four or five expert engineers, and that would mean a large expenditure of money. As it is now, I have one capable engineer and a good air compressor, and I keep my three wagons going all the time." He claims to spray 8,000 to 10,000 gallons a day. His apparatus, including the plant for making lime-sulphur wash, represents an investment of about 
$\$ 3,000$. I happen to know that he never stops to spray a tree, but goes straight along. He has the men on platforms on the side of the. wagon, and the wagon starts right off down between the rows, throwing the spray in a perfect cloud as it goes. As soon as the tank is empty, the next wagon comes up with its full tank, and connections are immediately made. The liquid is agitated by delivering compressed air at the bottom of the tank, and a precipitate is never found in the emptied tanks.

Secretary Burgess: The power sprayers on the market are assembled, that is, they are not built by one firm, and as a rule, the pumps are made for other purposes than spraying. The engines are also built for other purposes. Most of them are heavy stationary engines, which are simply hooked up with some pump. It seems to me that what is really needed is a spraying machine that is built for the purpose of spraying, rather than spraying machines that are built by assembling various parts-pumps, engines, etc.-which have been designed for other purposes. Professor Symons mentioned the idea of spraying from a tower. I believe the time is coming when we will give the fruit grower an equipment so that he can spray from no higher point than the top of the tank, or from the ground. I believe the system of solid stream spraying, properly adapted-it must be worked out and experimented with - can be used in any orchard, and the operator can spray from the ground.

Mr. Sruons: Those who spray for truck crops say that the Hillman sprayer has been found very satisfactory. It has a double acting pump which can be used for spraying trees if desired. There are several other satisfactory oncs on the market.

President Sanderson: I think it is very evident that we could spend more time on this subject. No one has mentioned the use of the gasoline engine with compressed air. It is very evident to all of us that what Mr. Burgess has said about the attitude of pump companies is very true. The insecticide companies have gone away in advance of the pump companies. I would like to suggest that when this symposium is published, it might be a good idea to send a marked copy to each of the pump companies. The next paper will be read by Mr. Webster. 